\title{
Produtividade e qualidade de grãos de canola em função da adubação nitrogenada e sulfatada ${ }^{1}$
}

\section{Yield and quality of canola grains due to nitrogen and sulfur fertilization}

\author{
Fábio Teixeira Lucas²*; Edson Luiz Mendes Coutinho3; \\ José Mauro Valente Paes ${ }^{4}$; José Carlos Barbosa ${ }^{5}$
}

\begin{abstract}
Resumo
O cultivo de canola (Brassica napus, L.) foi incentivado para produção de grãos para óleo na década de 1980, e também considerada boa opção para rotação de culturas. O nitrogênio é um dos nutrientes mais exigidos pela planta para aumento na produtividade, enquanto que o enxofre é essencial para proporcionar qualidade às sementes. Assim, objetivou-se avaliar, na região do Cerrado, os efeitos da adubação com nitrogênio e enxofre na produtividade e nos teores de óleo e proteína bruta nos grãos. Procurou-se, ainda, relacionar com a produtividade de grãos os teores de $\mathrm{S}$ no solo e as concentrações de $\mathrm{N}$ e $\mathrm{S}$ na folha diagnóstica. O experimento foi realizado no município de Uberaba, MG, em Latossolo Vermelho distrófico, textura média, utilizando-se o híbrido Hyola 401. Os tratamentos foram gerados pelo esquema fatorial $5 \times 4$ (cinco doses de $\mathrm{N}$ : 0, 60, 100, 140 e $180 \mathrm{~kg} \mathrm{ha}^{-1} \mathrm{e}$; quatro doses de S: 0, 15, 30 e $60 \mathrm{~kg} \mathrm{ha}^{-1}$ ) e dispostos em delineamento em blocos ao acaso, com quatro repetições. A adubação nitrogenada e sulfatada aumentou a produtividade de grãos de canola, sem alterar significativamente os

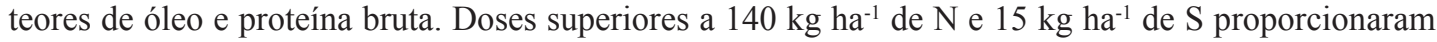
produtividades de grãos acima de $1100 \mathrm{~kg} \mathrm{ha}^{-1}$. Parcelas com produtividades de grãos superiores a $1000 \mathrm{~kg} \mathrm{ha}^{-1}$ apresentaram concentrações de $\mathrm{N}$ foliar acima de $52 \mathrm{~g} \mathrm{~kg}^{-1}$. Os maiores teores de $\mathrm{S}$ foram observados na camada de $15-30 \mathrm{~cm}$, comprovando mobilidade do ânion sulfato. As menores produtividades de grãos foram observadas quando os teores de $\mathrm{S}$ no solo nessa camada estavam menores que $4 \mathrm{mg} \mathrm{dm}^{-3}$. As concentrações de $\mathrm{N}$ na folha diagnóstica e os teores de $\mathrm{S}_{-} \mathrm{SO}_{4}^{-2}$ na camada de 15-30 $\mathrm{cm}$ relacionaram-se positivamente com a produtividade da cultura.
\end{abstract}

Palavras-chave: Brassica napus, nitrogênio, enxofre, óleo, proteína

\begin{abstract}
The canola (Brassica napus, L.) cultivation was encouraged for grain and oil production at the 80's, and it is also considered a good option for crop rotation. The nitrogen is one of the most required nutrients by the plant to increase its production, while sulfur is essential to provide seed quality. Thus, the objective of this study was, at Cerrado region, evaluate the effects of nitrogen and sulfur fertilization at yield and contents of oil and crude protein in the grains. We also sought relate to grain yield the $\mathrm{S}$ content in the
\end{abstract}

1 Parte da dissertação de mestrado do primeiro autor.

2 Discente de Doutorado do Curso de Pós-Graduação em Agronomia em Produção Vegetal, Dept ${ }^{\circ}$ de Solos e Adubos, Universidade Estadual Paulista "Júlio de Mesquita Filho", Faculdade de Ciências Agrárias e Veterinárias, UNESP/FCAV, Campus de Jaboticabal, SP. Bolsista da CAPES. E-mail: fabiotlucas@msn.com

3 Prof. Titular do Dept ${ }^{\circ}$ de Solos e Adubos, UNESP/FCAV, Campus de Jaboticabal, SP. E-mail: coutinho@fcav.unesp.br

${ }^{4}$ Pesquisador em Fitotecnia, Empresa de Pesquisa Agropecuária de Minas Gerais, Unidade Regional Triângulo Mineiro e Alto Paranaíba, Uberaba, MG. E-mail: jpaes@epamig.br

${ }^{5}$ Prof. Titular do Dept ${ }^{\circ}$ de Ciências Exatas da FCAV/UNESP, Campus de Jaboticabal, SP. E-mail: jcbarbosa@fcav.unesp.br

* Autor para correspondência 
soil and concentrations of $\mathrm{N}$ and $\mathrm{S}$ in the diagnosis leaf. The experiment was conducted in Uberaba County, State of Minas Gerais, Brazil, in an Oxisol, utilizing the Hyola 401 hybrid. The treatments consisted in a factorial scheme $5 \times 4$ (five $\mathrm{N}$ rates: 0, 60, 100, 140 and $180 \mathrm{~kg} \mathrm{ha}^{-1}$ and; four S rates: $0,15,30$ and $\left.60 \mathrm{~kg} \mathrm{ha}^{-1}\right)$ in a randomized blocks design, with four replicates. The nitrogen and sulfur fertilization increased canola grain yield, without significantly alter contents of oil and crude protein. Rates higher than to $140 \mathrm{~kg} \mathrm{ha}^{-1}$ of $\mathrm{N}$ and $15 \mathrm{~kg} \mathrm{ha}^{-1}$ of S provided grain yield above $1100 \mathrm{~kg} \mathrm{ha}^{-1}$. Plots with yield higher than to $1000 \mathrm{~kg} \mathrm{ha}^{-1}$ presented foliar concentration of $\mathrm{N}$ above $52 \mathrm{~g} \mathrm{~kg}^{-1}$. The highest $\mathrm{S}$ content was observed at the 0.15-0.30 m layer, proving the sulfate anion mobility. The lowest grain yield were observed when the $\mathrm{S}$ content in the soil at this layer were less than $4 \mathrm{mg} \mathrm{dm}^{-3}$. The $\mathrm{N}$ concentrations in the diagnostic leaf and $\mathrm{S}_{-} \mathrm{SO}_{4}^{-2}$ content in the 0.15-0.30 m layer correlated positively with crop yield.

Key words: Brassica napus, nitrogen, sulfur, oil, protein

\section{Introdução}

Existe grande interesse no cultivo da canola (Brassica napus, L.) na região Sudeste do Brasil devido a sua tolerância à seca e a possibilidade de utilizá-la em rotação com as culturas da soja, milho e feijão (TOMM, 2007). Segundo esse autor, o uso de cultivares menos sensíveis ao fotoperíodo favorece a adaptação da cultura ao clima tropical, apontando a canola como grande potencial na expansão do agronegócio do Cerrado em cultivo de safrinha (janeiro a abril). Além disso, existe facilidade na adaptação do conjunto de máquinas, comumente utilizado no cultivo de cereais, para o seu plantio e colheita, associado ao fato que, como planta produtora de óleo, nessa região concentra-se grande parte das indústrias de beneficiamento, tanto para óleo comestível quanto para a produção de biodiesel.

A exigência nutricional da cultura é considerada um dos fatores mais importantes, constituindo-se o nitrogênio $(\mathrm{N})$ como o nutriente que mais promove o incremento na produtividade de grãos de canola (CHEEMA et al., 2001; BRENNAN; BOLLAND, 2009). O excesso de N, ou a aplicação do mesmo em época inadequada, pode reduzir a produtividade e a qualidade dos grãos, diminuindo o teor de óleo e seu valor comercial (CHEEMA et al., 2001; AHMAD et al., 2007; JAN et al., 2010).

A canola é particularmente sensível à deficiência de enxofre (S), a qual reduz a produtividade e a qualidade dos grãos (SCHERER, 2001; MALHI; GILL, 2006; AHMAD et al., 2007).
Por outro lado, a exigência em $\mathrm{S}$ e o metabolismo dessenutriente em plantas estão também relacionados à nutrição nitrogenada, pois o metabolismo do $\mathrm{N}$ é fortemente afetado pela concentração de S na planta (MALHI, 2005; MALHI; GILL, 2007). Dentro desse contexto, Fismes et al. (2000), em condições de campo, verificaram que a deficiência de $\mathrm{S}$ em canola pode reduzir a eficiência de utilização do $\mathrm{N} \mathrm{e}$, ainda, que a carência de $\mathrm{N}$ pode, também, diminuir a eficiência de utilização de $\mathrm{S}$.

Devido à carência de estudos sobre nutrição e adubação da canola, o presente trabalho teve como objetivos avaliar, na região do Cerrado, os efeitos da adubação com nitrogênio e enxofre na produtividade e nos teores de óleo e proteína bruta nos grãos. Procurou-se, ainda, relacionar com a produtividade de grãos os teores de $\mathrm{S}$ no solo e as concentrações de $\mathrm{N}$ e $\mathrm{S}$ na folha diagnóstica.

\section{Material e Métodos}

O experimento foi conduzido, em condições de campo, na área experimental do Instituto Federal do Triângulo Mineiro - IFTM, Campus de Uberaba,

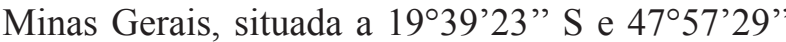
$\mathrm{W}$, a $798 \mathrm{~m}$ de altitude. A região apresenta clima tropical semi-úmido.

O solo da área experimental é classificado como Latossolo Vermelho distrófico textura média (EMBRAPA, 2006). Os atributos químicos do solo, determinados segundo Raij et al. (2001), encontramse na Tabela 1. 
Com o objetivo de elevar a saturação por bases a $70 \%$, foi aplicada, 60 dias antes da semeadura, 1,9 $\mathrm{t}$ ha ${ }^{-1}$ de calcário $(\mathrm{PRNT}=85,08 \%$; $\mathrm{PN}=99,87 \%$;
$\mathrm{CaO}=36,40 \% ; \mathrm{MgO}=14,00 \%) . \mathrm{O}$ material corretivo da acidez foi incorporado, por meio de aração e gradagem, até a profundidade de $20 \mathrm{~cm}$.

Tabela 1. Análise química para fins de fertilidade do solo na camada de 0 a $20 \mathrm{~cm}$.

\begin{tabular}{|c|c|c|c|c|c|c|c|c|c|}
\hline$\underset{\mathrm{CaCl}_{2}}{\mathbf{p H}}$ & 1/M.O. & $\begin{array}{c}\mathbf{P} \\
\text { Resina }\end{array}$ & $\mathbf{K}$ & $\mathrm{Ca}$ & Mg & $\mathbf{H}+\mathbf{A l}$ & ${ }^{2 / C T C}$ & ${ }^{3 /} \mathbf{V}$ & $\mathrm{S}-S O_{4}$ \\
\hline & $\mathrm{g} \mathrm{dm}^{-3}$ & $\mathrm{mg} \mathrm{dm}^{-3}$ & & - & $-\mathrm{mm}$ & $\mathrm{dm}^{-3}-$ & - & $\%$ & $\mathrm{mg} \mathrm{dm}^{-3}$ \\
\hline 4,7 & 12 & 30 & 0,9 & 13 & 4 & 31 & 48,9 & 37 & 2 \\
\hline
\end{tabular}

${ }^{1}$ M.O. = Matéria orgânica;

${ }^{2} \mathrm{CTC}=$ Capacidade de troca de cátions;

${ }^{3 /} \mathrm{V}=$ Saturação por bases.

Fonte: Elaboração dos autores.

As sementes de canola (híbrido Hyola 401) foram distribuídas a uma profundidade de 2 a 3 cm, no dia 28/08/2010. Devido à utilização de excesso de sementes, 12 dias após a emergência das plântulas, foi realizado desbaste para proporcionar uma população de, aproximadamente, 30 plantas $\mathrm{m}^{-2}$.

Os tratamentos foram gerados pelo esquema fatorial 5 x 4 (cinco doses de N: 0, 60, 100, 140 e $180 \mathrm{~kg} \mathrm{ha}^{-1}$ e; quatro doses de $\mathrm{S}: 0,15,30$ e 60 $\mathrm{kg} \mathrm{ha}^{-1}$ ) e dispostos em delineamento em blocos ao acaso, com quatro repetições. As parcelas foram compostas por cinco linhas de cinco metros de comprimento, espaçadas de $0,45 \mathrm{~m}$ entre si, com área total de $11,25 \mathrm{~m}^{2}$ e área útil constituída pelas três linhas centrais $\left(6,75 \mathrm{~m}^{2}\right)$. As unidades experimentais foram separadas por carreadores de $1,0 \mathrm{~m}$ de comprimento.

As doses de $\mathrm{N}$ foram parceladas da seguinte maneira: $20 \mathrm{~kg} \mathrm{ha}^{-1}$ de $\mathrm{N}$ na semeadura (exceto no tratamento sem $\mathrm{N}$ ), e o restante da dose foi aplicada em cobertura quando as plântulas apresentavam quatro folhas completas, segundo recomendação de Tomm (2007), correspondendo a 30 dias após a semeadura. A fonte de adubação nitrogenada utilizada foi a ureia.

As doses de enxofre foram aplicadas utilizandose como fonte o superfosfato simples. Esse fertilizante atuou também como fonte de fósforo sendo que o que faltou para integralizar a dose desse nutriente $\left(100 \mathrm{~kg} \mathrm{ha}^{-1}\right.$ de $\left.\mathrm{P}_{2} \mathrm{O}_{5}\right)$ foi complementado com superfosfato triplo. No tratamento sem $\mathrm{S}$, foi utilizado o superfosfato triplo como fonte de adubação fosfatada.

Todos os tratamentos receberam, além do fósforo, adubação constante com $120 \mathrm{~kg} \mathrm{ha}^{-1}$ de $\mathrm{K}_{2} \mathrm{O}$, utilizando-se como fonte o cloreto de potássio. A adubação com ureia, superfosfato simples, superfosfato triplo e cloreto de potássio foi realizada a lanço, com posterior incorporação com grade, três dias antes da semeadura.

Para avaliação dos teores foliares de $\mathrm{N}$ e $\mathrm{S}$, no início do florescimento (43 dias após a emergência das plântulas), foi coletada, de 30 plantas por parcela, a folha mais recentemente desenvolvida, correspondendo à segunda folha a partir da inflorescência. Na mesma época, foi realizada amostragem de solo para determinar os teores de $\mathrm{S}_{-} \mathrm{SO}_{4}^{-2}$ em duas profundidades (0-15 e $15-30 \mathrm{~cm}$ ). Em cada parcela foram coletadas, nas entrelinhas, 12 amostras simples, as quais, após homogeneização, deram origem à amostra composta. Esse procedimento foi realizado para cada profundidade de amostragem de solo.

No dia 22/12/2010, na área útil de cada parcela, efetuou-se a colheita utilizando-se o sistema de 
corte e enleiramento. As plantas foram colhidas inteiras, cortando-se as raízes no campo, enleiradas e colocadas para secar em casa de vegetação durante cinco dias. Logo após, procedeu-se, manualmente, a trilhagem. A produtividade de grãos foi ajustada a 9 $\%$ de umidade, conforme recomendação de Tomm (2007).

Determinou-se a massa de 1000 grãos e os teores de óleo e proteína bruta nos grãos. Para a determinação da massa de 1000 grãos foi realizada, por parcela, contagem manual em triplicata e, em seguida, utilizada uma balança analítica com precisão de 0,01 g. Foi considerada, para análise estatística, a média das três pesagens por parcela. $\mathrm{O}$ teor de proteína foi estimado através da determinação da concentração de $\mathrm{N}$ total nos grãos, expresso em g de $\mathrm{N} \mathrm{kg}^{-1}$ de massa seca, multiplicado por 0,625 (SILVA; QUEIROZ, 2002).

Para avaliação do teor de óleo foi utilizado extrator de Soxhlet (SILVA; QUEIROZ, 2002).

As análises químicas das folhas e dos grãos (concentrações de $\mathrm{N}$ e $\mathrm{S}$ ) foram realizadas empregando-se metodologia descrita por Bataglia et al. (1983). Para a determinação da concentração de $\mathrm{N}$ foi feita a digestão com $\mathrm{H}_{2} \mathrm{SO}_{4}$ e $\mathrm{H}_{2} \mathrm{O}_{2}$ utilizandose um semimicro-Kjeldahl. Para a determinação da concentração de S, inicialmente, procedeuse à digestão nitroperclórica. A determinação turbidimétrica do sulfato baseou-se na turbidez formada pela precipitação do $\mathrm{S}$ pelo $\mathrm{BaCl}_{2}$, na forma de $\mathrm{BaSO}_{4}$, turbidez essa medida em espectofotômetro.

Para análise de $\mathrm{S}$ no solo, a metodologia utilizada foi a descrita por Cantarella e Prochnow (2001). A extração do sulfato das amostras de solo foi realizada com uma solução de $\mathrm{CaSO}_{4} 0,01 \mathrm{~mol}$ $\mathrm{L}^{-1}$. A quantificação foi feita por turbidimetria, provocado pela presença de $\mathrm{BaSO}_{4}$, formado pela reação do $\mathrm{BaCl}_{2}$ com o $\mathrm{S}-\mathrm{SO}_{4}^{-2}$. A turbidez foi medida em espectofotômetro.
Durante o período experimental, foi realizada irrigação utilizando-se de um sistema autopropelido tipo canhão, conforme metodologia de Allen et al. (2006).

As análises estatísticas foram realizadas utilizando-se o pacote estatístico AgroEstat (BARBOSA; MALDONADO JÚNIOR, 2011). Os dados foram submetidos à análise de variância pelo teste $\mathrm{F}$ a $5 \%$ de probabilidade e, quando constatadas diferenças significativas, realizaram-se estudos de regressão. Para produtividade de grãos ajustou-se uma superfície de resposta polinomial de segunda ordem em função das doses de $\mathrm{N}$ e S utilizando-se o programa Statistica versão 10.0 .

\section{Resultados e Discussão}

Doses crescentes de $\mathrm{N}$ aumentaram a concentração desse nutriente nas folhas $\left(\mathrm{F}=33,65^{* *}\right)$ (Figura 1). Também, a concentração de $\mathrm{S}$ nas folhas aumentou com o incremento nas doses de $\mathrm{S}(\mathrm{F}=$ $3,54^{*}$ ) (Figura 2).

$\mathrm{Na}$ ausência da adubação nitrogenada, as concentrações de $\mathrm{N}$ nas folhas foram próximas a 42 $\mathrm{g} \mathrm{kg}^{-1}$, podendo ser consideradas como deficientes para a cultura da canola. Em comparação com as plantas que receberam $\mathrm{N}$ na adubação, as plantas das parcelas sem esse nutriente eram menores, com folhas mais velhas cloróticas e, visivelmente, apresentavam menores quantidades de ramos e de vagens, caracterizando sintomas clássicos de carência de N. Não foram verificados sintomas visuais de deficiência de $\mathrm{S}$ nas plantas.

É importante mencionar, ainda, que o procedimento adotado para fins de diagnose foliar (época e folha amostrada) foi adequado, tendose em vista as relações significativas observadas entre as doses de $\mathrm{N}$ e $\mathrm{S}$ e as concentrações desses nutrientes nas folhas. 
Figura 1. Concentrações de $\mathrm{N}$ na folha diagnóstica de canola no início do florescimento em função da adubação nitrogenada.

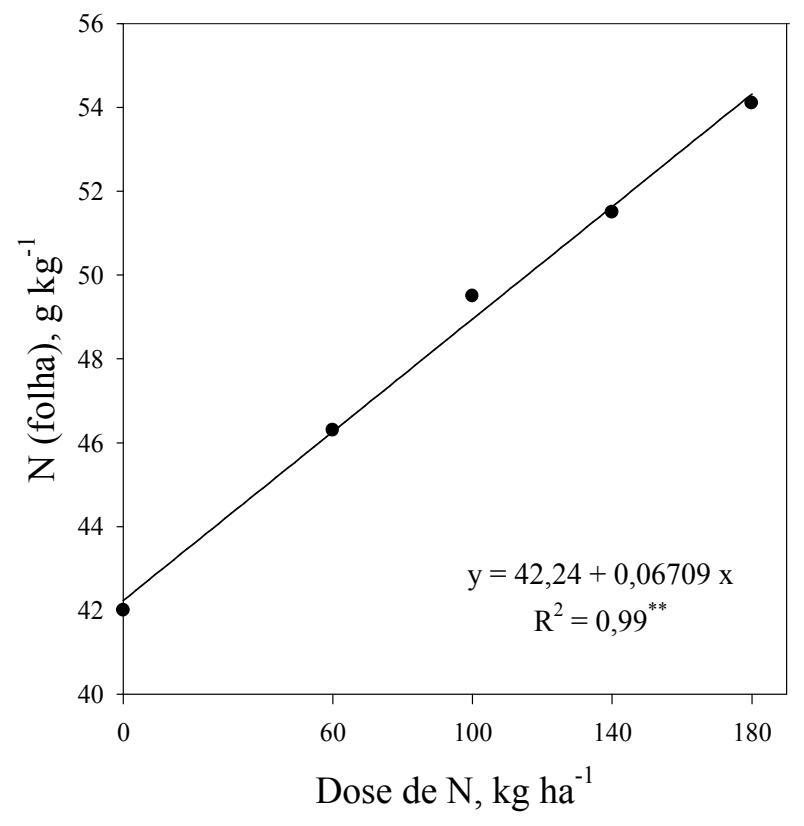

Fonte: Elaboração dos autores.

Figura 2. Concentrações de S na folha diagnóstica de canola no início do florescimento em função da adubação sulfatada.

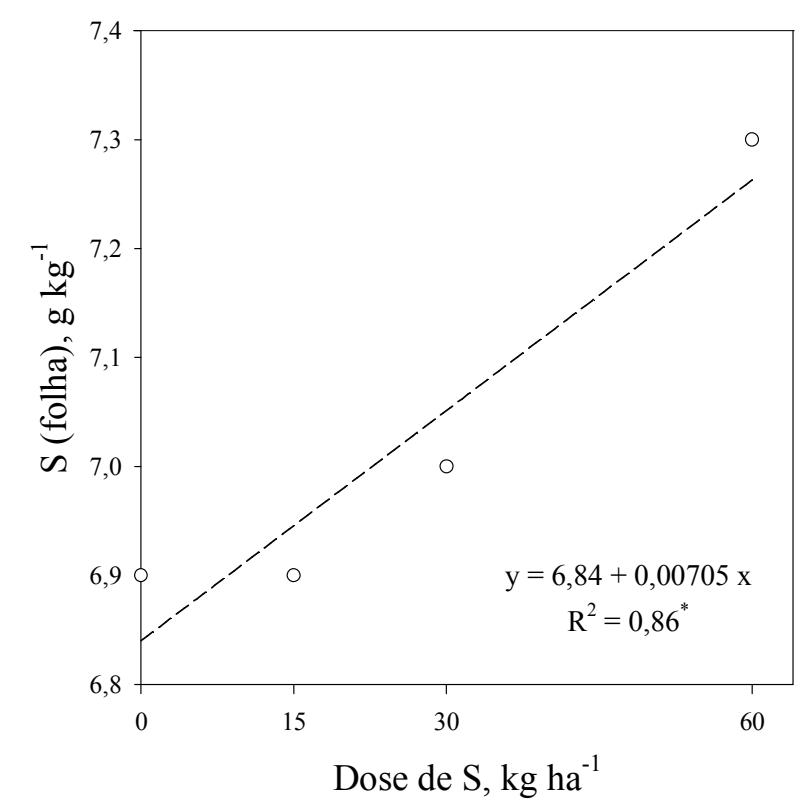

Fonte: Elaboração dos autores. 
Hocking et al. (1997), utilizando a folha mais jovem da planta de canola amostrada quando as plantas apresentavam $50 \%$ de florescimento, também verificaram aumento na concentração de $\mathrm{N}$ com a adubação nitrogenada com as concentrações desse nutriente variando de 40 a $60 \mathrm{~g} \mathrm{~kg}^{-1}$, valores estes próximos aos encontrados no presente trabalho.

Por outro lado, sabe-se que os metabolismos do $\mathrm{N}$ e do $\mathrm{S}$ estão diretamente relacionados, sendo que a deficiência de um deles pode afetar a via de assimilação do outro (KOPRIVOVA et al., 2000). Neste sentido, Fismes et al. (2000) verificaram que a deficiência de $\mathrm{N}$ em canola reduziu a eficiência de utilização do $\mathrm{S}$.
No presente trabalho isso não foi constatado, uma vez que sintomas de carência de $\mathrm{N}$ foram verificados somente nas plantas que não receberam $\mathrm{N}$, mas o fornecimento desse nutriente não afetou a assimilação de $\mathrm{S}$, visto que não houve interação significativa entre as doses de $\mathrm{N}$ e $\mathrm{S}$ em relação à concentração de $\mathrm{N}\left(\mathrm{F}=0,27^{\mathrm{ns}}\right)$ e $\mathrm{S}\left(\mathrm{F}=0,54^{\mathrm{ns}}\right)$ nas folhas.

No solo, a adubação com $\mathrm{S}$ aumentou os teores desse nutriente tanto na camada de $0-15 \mathrm{~cm}(\mathrm{~F}=$ $\left.11,79^{* *}\right)$ quanto na de $15-30 \mathrm{~cm}\left(\mathrm{~F}=28,36^{* *}\right)$. Não houve interação significativa entre as doses de $\mathrm{N}$ e $\mathrm{S}$ em relação aos teores de $\mathrm{S}$ no solo nas camadas de $0-15 \mathrm{~cm}\left(\mathrm{~F}=0,52^{\mathrm{ns}}\right)$ e de $15-30 \mathrm{~cm}(\mathrm{~F}$ $\left.=0,30^{\mathrm{ns}}\right)$. Os maiores teores de $\mathrm{S}$ foram observados na camada de 15-30 cm (Figura 3), comprovando mobilidade do ânion sulfato (ERIKSEN; OLESEN; ASKEGAARD, 2002).

Figura 3. Teores de $\mathrm{S}$ no solo nas camadas de 0-15 e 15-30 cm no início do florescimento em função da adubação sulfatada.

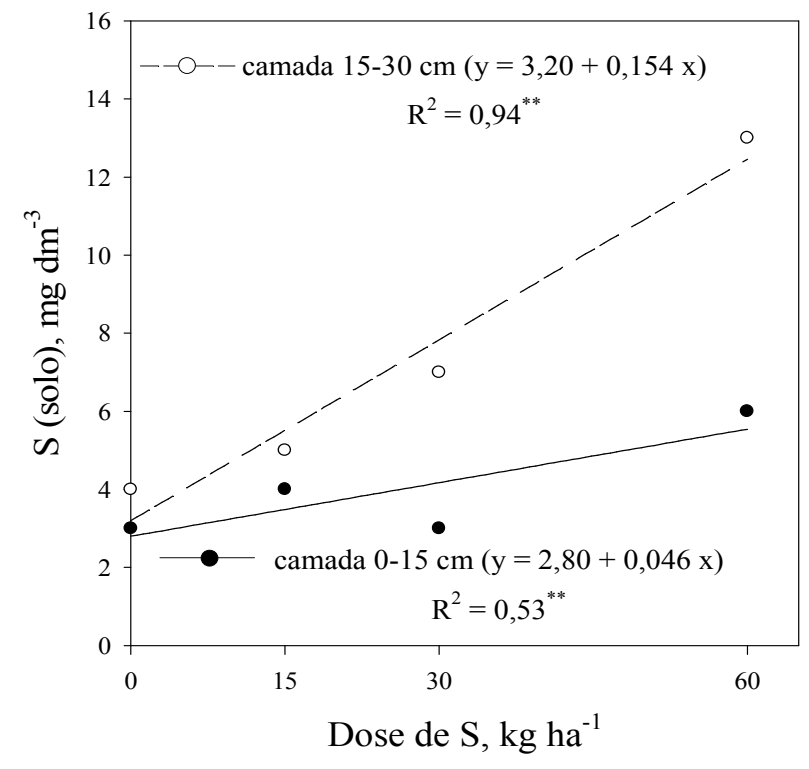

Fonte: Elaboração dos autores.

Em relação à produtividade de grãos, houve interação significativa $\left(\mathrm{F}=5,09^{* *}\right)$ entre as doses de $\mathrm{N}$ e S, concordando com Fismes et al. (2000), Malhi (2005) e Malhi e Gill (2007), que também verificaram interação entre esses nutrientes, afirmando que a deficiência de $\mathrm{S}$ em canola pode reduzir a eficiência de utilização do $\mathrm{N}$ e, ainda, que a deficiência de $\mathrm{N}$ pode também reduzir a eficiência 
de utilização de $\mathrm{S}$, interferindo negativamente na produtividade de grãos.

As médias da produtividade de grãos em cada combinação de $\mathrm{N}$ e $\mathrm{S}$ podem ser vistas na Tabela 2. A Figura 4 apresenta as combinações das doses de $\mathrm{N}$ e $\mathrm{S}$ que induzem a uma mesma produtividade (isolinhas) e representa cortes realizados na superfície de resposta polinomial de segunda ordem nas produtividades esperadas. Verifica-se que houve incrementos na produtividade de grãos na medida em que foram aumentadas as doses de $\mathrm{N}$ e $\mathrm{S}$.

Nota-se que para produtividades de grãos mais elevadas do que $1100 \mathrm{~kg} \mathrm{ha}^{-1}$ são necessárias doses superiores a $140 \mathrm{~kg} \mathrm{ha}^{-1}$ de $\mathrm{N}$ e $15 \mathrm{~kg} \mathrm{ha}^{-1}$ de S.

Tabela 2. Médias da produtividade de grãos de canola em cada combinação de $\mathrm{N} \mathrm{e} \mathrm{S}$, em kg ha-1.

\begin{tabular}{|c|c|c|c|c|c|c|}
\hline \multirow{2}{*}{$\begin{array}{c}\text { Dose de N } \\
\left(\mathrm{kg} \mathrm{ha}^{-1}\right)\end{array}$} & \multicolumn{4}{|c|}{ Dose de S (kg ha-1) } & \multirow{2}{*}{ Média } & \multirow{2}{*}{ Teste F } \\
\hline & 0 & 15 & 30 & 60 & & \\
\hline 0 & 715 & 725 & 673 & 724 & 709 & $0,22^{\mathrm{ns}}$ \\
\hline 60 & 732 & 763 & 781 & 781 & 764 & $3,99^{*}$ \\
\hline 100 & 813 & 936 & 959 & 959 & 917 & $11,68^{* *}$ \\
\hline 140 & 854 & 1048 & 878 & 1109 & 972 & $5,68^{* *}$ \\
\hline 180 & 1040 & 967 & 1326 & 1195 & 1132 & $9,27^{* *}$ \\
\hline Média & 831 & 888 & 923 & 954 & 899 & ${ }^{1 / C . V .(\%)}$ \\
\hline Teste F & $6,12^{* *}$ & $6,86^{* *}$ & $29,84^{* *}$ & $11,56^{* *}$ & $5,09^{* *}$ & 11,43 \\
\hline
\end{tabular}

ns: não significativo ao nível de $5 \%$ de probabilidade pelo teste $\mathrm{F}$;

*: significativo ao nível de $5 \%$ de probabilidade pelo teste $\mathrm{F}$;

${ }^{* *}$ : significativo ao nível de $1 \%$ de probabilidade pelo teste $\mathrm{F}$;

${ }^{1 / C . V .: ~ C o e f i c i e n t e ~ d e ~ v a r i a c ̧ a ̃ o . ~}$

Fonte: Elaboração dos autores.

Figura 4. Isolinhas de produtividade de grãos de canola em função da adubação nitrogenada e sulfatada.

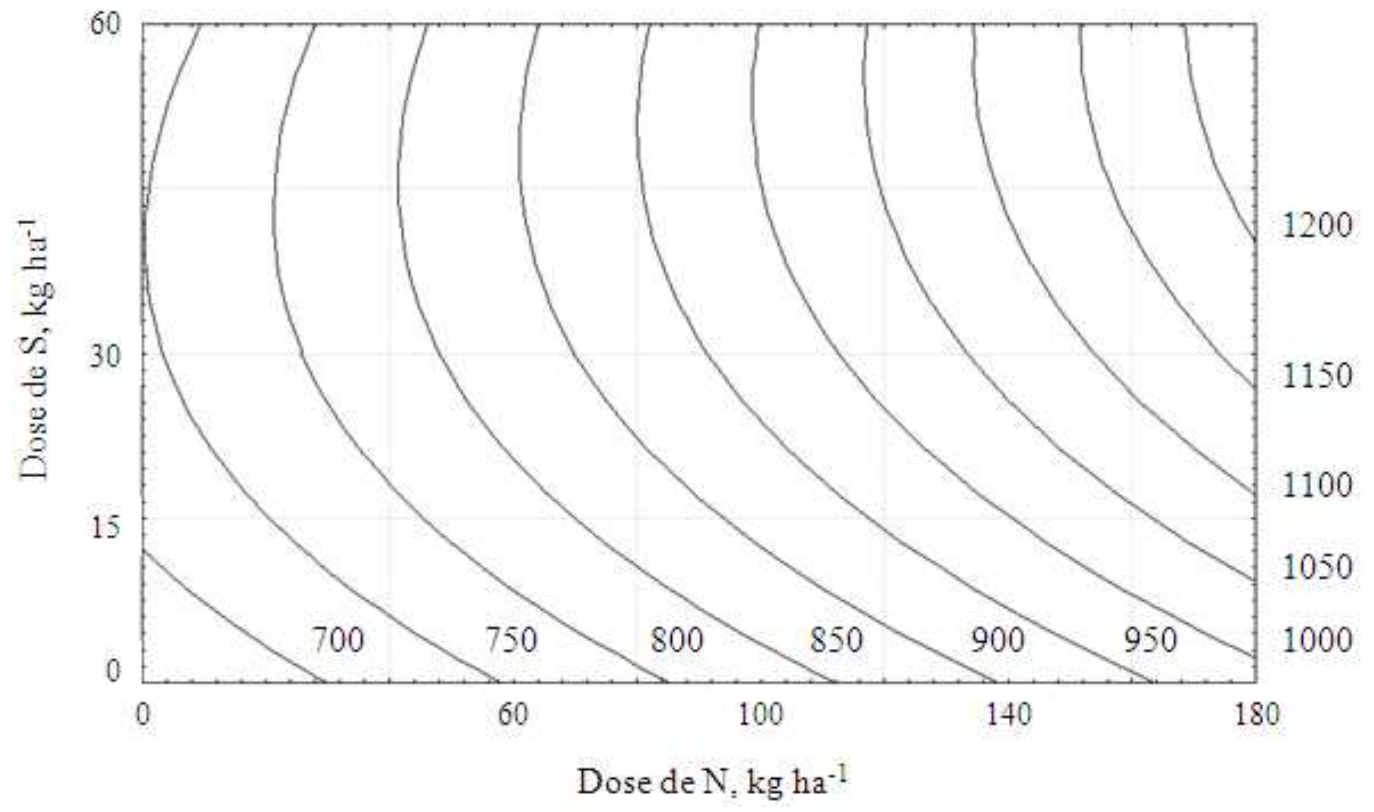

Produtividade de grãos $\left(\mathrm{kg} \mathrm{ha}^{-1}\right)=648,358+1,709 \mathrm{~N}+5,011 \mathrm{~S}+0,000826 \mathrm{~N}^{2}+0,016222 \mathrm{NxS}-0,062370 \mathrm{~S}^{2}$ $\mathrm{R}^{2}=0,72^{* *}$.

Fonte: Elaboração dos autores. 
Alguns trabalhos relatam que, em termos de produtividade de grãos de canola, a exigência de $\mathrm{S}$ tende a aumentar com o incremento da quantidade de N aplicado (MALHI, 2005; MALHI; GILL, 2006; AHMAD et al., 2007). Rubio et al. (2007) observaram baixo incremento na produtividade de grãos em aplicações isoladas de N e S. Porém, a adição simultânea de ambos os nutrientes ocasionou aumento de $56 \%$ na produtividade, ressaltando a importância do S juntamente à adubação nitrogenada, conforme observado no presente trabalho.

Öztürk (2010) verificou que a produtividade de grãos aumentou até a dose de $150 \mathrm{~kg} \mathrm{ha}^{-1}$ de $\mathrm{N}$, porém sendo superior ao presente trabalho (3165 $\mathrm{kg} \mathrm{ha}^{-1}$ ). Já Ibrahim, Abusteit e El-Metwally (1989) verificaram que a produtividade aumentou com doses de $\mathrm{N}$ até $213 \mathrm{~kg} \mathrm{ha}^{-1}$. No entanto, alguns autores observaram redução na produtividade de grãos ao se utilizar doses acima de $120 \mathrm{~kg} \mathrm{ha}^{-1}$ de N (CHEEMA et al., 2001; JAN et al., 2010).

Assim, o $\mathrm{N}$ pode ser considerado como um dos nutrientes mais importantes para o incremento na produtividade de grãos de canola, podendo favorecer o desenvolvimento da área foliar, retardando a senescência foliar e beneficiando a floração (BRENNAN; BOLLAND, 2009).

Segundo Epstein e Bloom (2006), a interação $\mathrm{N}$ e $\mathrm{S}$ deve ser levada em consideração nas recomendações de adubação. A utilização de fórmulas de adubo concentradas, sem $\mathrm{S}$, pode ocasionar um baixo aproveitamento do N. Boa parte do $\mathrm{N}$ nas plantas está em forma de proteínas. O S é constituinte de dois aminoácidos (cisteína e metionina). A sua deficiência ocasiona a diminuição da produção desses aminoácidos e as proteínas que os contêm não podem ser formadas. Devido a isso, plantas insuficientemente supridas com $\mathrm{S}$ não conseguem assimilar o $\mathrm{N}$ em proteínas e o $\mathrm{N}$ se acumula na forma de aminas, amidas e aminoácidos solúveis. Assim, a importância do equilíbrio entre as concentrações de $\mathrm{N}$ e $\mathrm{S}$ no solo e na planta é refletida no crescimento e no estado nutricional, ou seja, doses mais altas de um desses elementos podem levar à menor disponibilidade do outro elemento para as plantas, prejudicando o rendimento da cultura.

De acordo com Malhi e Gill (2007), o uso de fertilizantes sulfatados é fundamental para obter resposta positiva da canola à adubação nitrogenada em relação à produtividade, concentração de $\mathrm{S}$, óleo e proteína nos grãos. A resposta da aplicação de $\mathrm{S}$ em canola, segundo os autores, é em altas doses de $\mathrm{N}$. Os mesmos afirmam que, considerando a alta exigência de $\mathrm{S}$ pela canola, quando utilizado solo com baixos teores desse nutriente, pode-se esperar resposta à fertilização sulfatada.

Verifica-se na Figura 5 que a produtividade de grãos relacionou-se significativamente com as concentrações de $\mathrm{N}$ nas folhas. Nota-se que produtividades superiores a $1000 \mathrm{~kg} \mathrm{ha}^{-1}$ estiveram associadas a concentrações de $\mathrm{N}$ nas folhas acima de $52 \mathrm{~g} \mathrm{~kg}^{-1}$.

Também, esse nutriente pode proporcionar aumento nos números de vagens, de ramos por planta e de grãos por vagem, além de aumentar a massa de 1000 grãos (ÖZTÜRK, 2010), conforme verificado no presente trabalho (Figura 6), resultando em maiores produtividades. 
Figura 5. Produtividade de grãos de canola em função das concentrações de $\mathrm{N}$ na folha diagnóstica no início do florescimento.

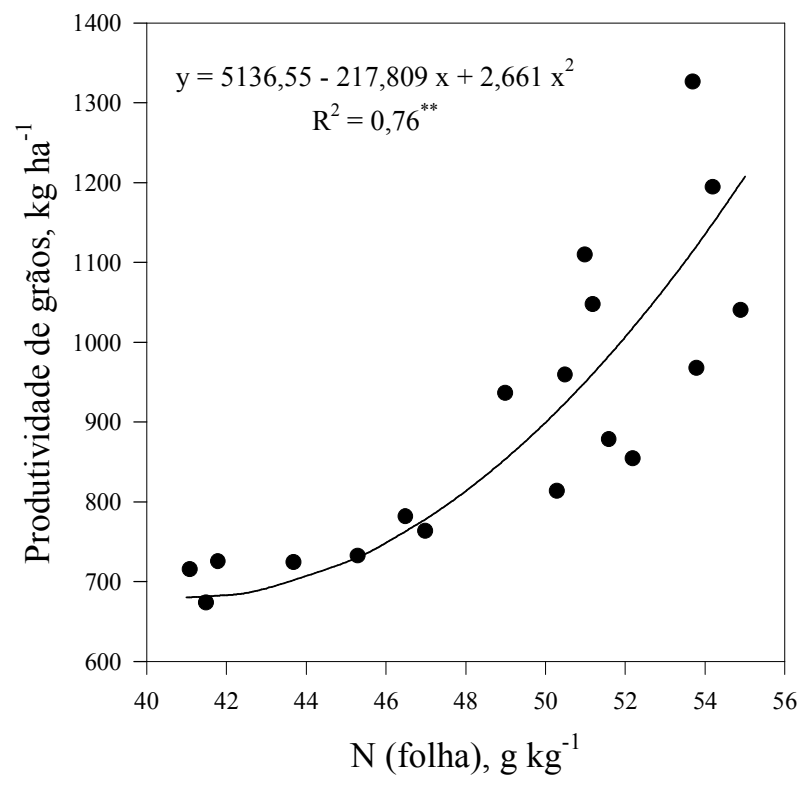

Fonte: Elaboração dos autores.

Figura 6. Massa de 1000 grãos de canola em função da adubação nitrogenada e sulfatada.

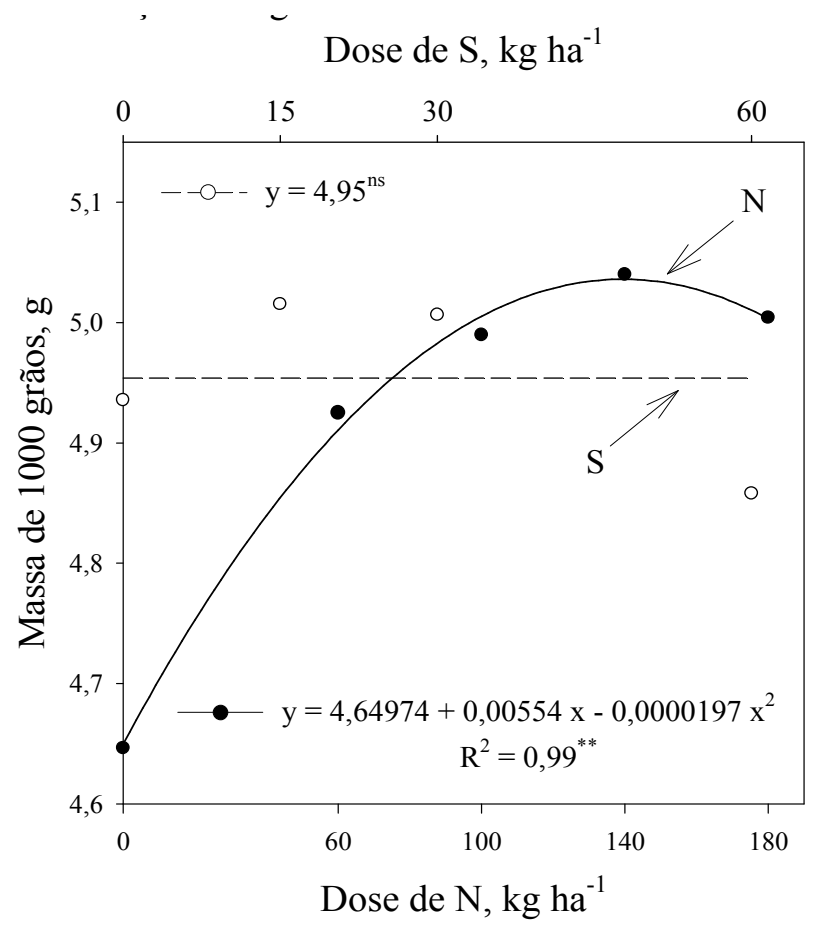

Fonte: Elaboração dos autores. 
Observa-se na Figura 6 que apenas o N (doses até $\left.140 \mathrm{~kg} \mathrm{ha}^{-1}\right)$ proporcionou incremento na massa de 1000 grãos $\left(\mathrm{F}=5,11^{* *}\right)$, corroborando resultados obtidos por Öztürk (2010).

Não foi verificada interação significativa entre as doses de $\mathrm{N}$ e $\mathrm{S}$ em relação à massa de 1000 grãos $\left(\mathrm{F}=1,03^{\mathrm{ns}}\right)$. Possivelmente, o $\mathrm{S}$ foi importante para aumentar a quantidade de grãos, enquanto que o $\mathrm{N}$, além da quantidade, deve ter aumentado o tamanho e a massa do grão. No entanto, deve-se considerar que o S, também, é um elemento importante para o crescimento das plantas por estar presente em vários compostos metabólicos (SCHERER, 2001) contribuindo, também, para aumentar o sistema radicular, conteúdo de clorofila nas folhas e a produtividade de grãos (ZHAO et al., 2008). Scherer (2001) relatou que a canola é sensível à limitação ou deficiência de $\mathrm{S}$, a qual reduz a produtividade de grãos em aproximadamente $40 \%$.

Malhi (2005) observou que a aplicação de 15 a $30 \mathrm{~kg} \mathrm{ha}^{-1}$ de $\mathrm{S}$ na maioria dos solos deficientes é suficiente para otimizar a produtividade de grãos, conforme observado no presente trabalho (Figura 4).
Conforme relatado anteriormente, o $\mathrm{S}$ aplicado migrou em maior quantidade para a camada de 15-30 cm, sendo esse comportamento de grande importância prática para uma correta amostragem de solo para fins de diagnóstico da disponibilidade de $\mathrm{S}$ e recomendação de adubação sulfatada. Nesse sentido, no Estado de São Paulo, Raij et al. (1996) recomendam a análise de amostras de subsolo para avaliar a disponibilidade de $\mathrm{S}$, pois o sulfato tende a acumular nessa camada.

Apesardas controvérsias sobre a interpretação dos níveis de suficiência de $\mathrm{S}$ no solo (RHEINHEIMER et al., 2005), parece que as faixas de concentração sugeridas por Raij et al. (1996) foram adequadas para a cultura da canola. Nota-se na Figura 7 que baixas produtividades de grãos foram obtidas quando os teores de $\mathrm{S}$ no solo (camada de 15-30 $\mathrm{cm})$ estavam baixos $\left(<4 \mathrm{mg} \mathrm{dm}^{-3}\right)$.

Quando avaliados os teores de óleo e proteína nos grãos, verificou-se que não houve diferença significativa entre as doses de $\mathrm{N}$ e S (Tabela 3).

Tabela 3. Teores de óleo e proteína bruta nos grãos de canola em função da adubação nitrogenada e sulfatada.

\begin{tabular}{|c|c|c|}
\hline Causas de Variação & Óleo & Proteína Bruta \\
\hline Dose de N $\left(\mathrm{kg} \mathrm{ha}^{-1}\right)$ & $-----\cdot$ & 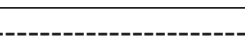 \\
\hline 0 & 31,7 & 27,8 \\
\hline 60 & 32,8 & 28,7 \\
\hline 100 & 32,5 & 27,8 \\
\hline 140 & 32,2 & 26,9 \\
\hline 180 & 31,7 & 27,7 \\
\hline Teste F & $0,78^{\text {ns }}$ & $0,60^{\mathrm{ns}}$ \\
\hline \multicolumn{3}{|l|}{ Dose de $\mathrm{S}\left(\mathrm{kg} \mathrm{ha}^{-1}\right)$} \\
\hline 0 & 32,0 & 27,4 \\
\hline 15 & 31,7 & 28,8 \\
\hline 30 & 33,1 & 27,3 \\
\hline 60 & 31,8 & 27,7 \\
\hline Teste F & $1,80^{\text {ns }}$ & $0,89^{\mathrm{ns}}$ \\
\hline \multicolumn{3}{|l|}{ Interação N x S } \\
\hline Teste F & $1,04^{\text {ns }}$ & $0,72^{\mathrm{ns}}$ \\
\hline${ }^{1 / C . V . ~(\%) ~}$ & 6,84 & 11,57 \\
\hline
\end{tabular}

ns: não significativo ao nível de $5 \%$ de probabilidade pelo teste $\mathrm{F}$;

${ }^{1 / C}$ C.V.: Coeficiente de variação.

Fonte: Elaboração dos autores. 
Figura 7. Produtividade de grãos de canola em função dos teores de S no solo no início do florescimento.

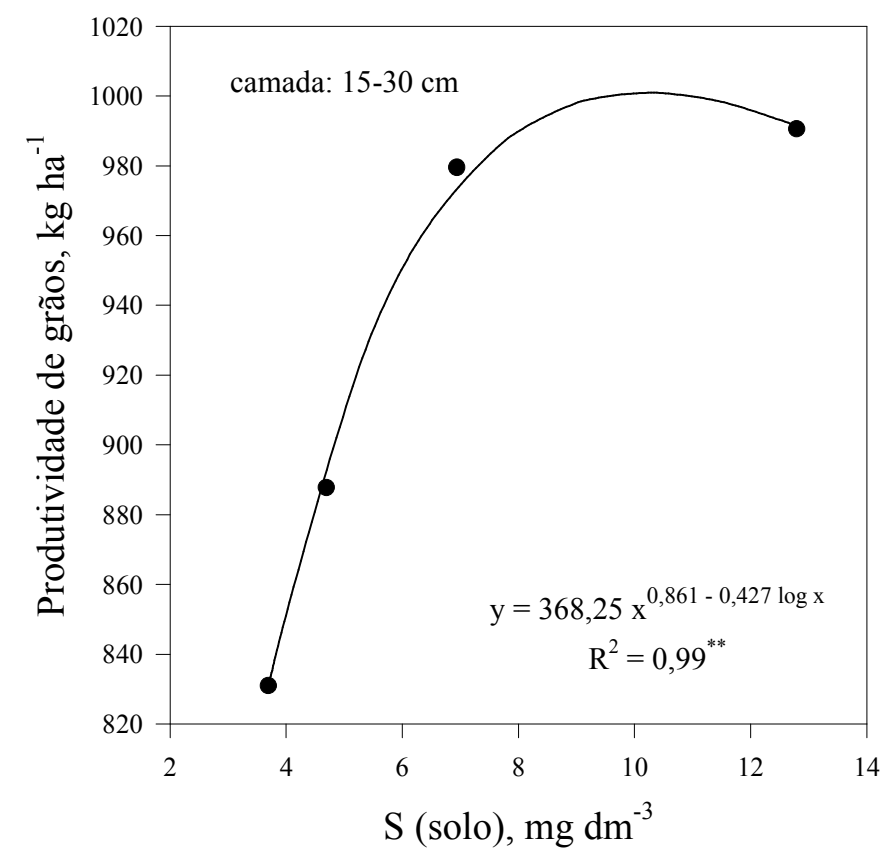

Fonte: Elaboração dos autores.

No entanto, há controvérsia sobre a influência da adição de $\mathrm{N}$ e $\mathrm{S}$ nos teores de óleo e proteína nos grãos de canola. Ao contrário do presente trabalho, alguns autores verificaram incrementos significativos das doses desses nutrientes nos teores de óleo e proteína nos grãos de canola.

Rathke, Christen e Diepenbrock (2005), Ahmad et al. (2007) e Jan et al. (2010) verificaram tendência na diminuição do teor de óleo com a utilização de doses de $\mathrm{N}$ acima de $80 \mathrm{~kg} \mathrm{ha}^{-1}$. Cheema et al. (2001) e Rathke, Christen e Diepenbrock (2005) relataram que essa diminuição pode ser devida à menor disponibilidade de carboidratos para a síntese de óleo quando na presença de altas doses de N. Segundo Khan et al (2002), essa redução pode ocorrer, pois há relação inversa entre os teores de óleo e proteína nos grãos, ou seja, altas doses de $\mathrm{N}$ aumentam o teor de proteína e, consequentemente, ocasionam a diminuição no teor de óleo. Ali et al. (2003), Rathke, Christen e Diepenbrock (2005) e Jan et al. (2010) também verificaram que o aumento das doses de $\mathrm{N}$ aumentou o teor de proteína nos grãos.

Em relação ao $\mathrm{S}$, alguns autores verificaram que doses crescentes aumentaram progressivamente os teores de óleo e proteína, sendo considerado um nutriente importante na qualidade, além de desempenhar papel importante na composição química dos grãos (KHAN et al., 2002; MALIK et al., 2004; MALHI, 2005; MALHI; GILL, 2006; AHMAD et al., 2007).

No presente trabalho foram encontrados teores de óleo entre 31,7 e 33,1 \% e teores de proteína entre 26,9 e $28,8 \%$, próximos aos observados no Brasil por Tomm (2007). Assim, embora na literatura consultada tenham sido encontrados alguns trabalhos relatando incrementos significativos do $\mathrm{N}$ e do $\mathrm{S}$ nos teores de óleo e proteína, uma possível justificativa para a ausência de resposta significativa à adubação nitrogenada e sulfatada pode ser devida à característica genética do híbrido utilizado. Tratase de um híbrido rústico, o que proporciona a sua 
utilização em amplos ambientes edafoclimáticos. Com essas características, possivelmente, a influência da adubação nos teores de óleo e proteína pode ter ficado em segundo plano no processo de melhoramento genético.

Assim, concluiu-se que a adição de $\mathrm{N}$ e $\mathrm{S}$ aumentou a produtividade de grãos de canola, sem alterar significativamente os teores de óleo e proteína bruta; As concentrações de $\mathrm{N}$ na folha diagnóstica e os teores de $\mathrm{S}_{-} \mathrm{SO}_{4}^{-2}$ na camada de $15-30 \mathrm{~cm}$ relacionaram-se positivamente com a produtividade da cultura.

\section{Agradecimentos}

À CAPES, pela bolsa de Mestrado concedida ao primeiro autor;

Às instituições FCAV-UNESP, EPAMIGURETP, EMBRAPA TRIGO, FAZU, IFTM, VALE FERTILIZANTES e CERTRIM, pelo apoio na realização do experimento.

\section{Referências}

AHMAD, G.; JAN, A.; ARIF, M.; JAN, M. T.; KHATTAK, R. A. Influence of nitrogen and sulfur fertilization on quality of canola (Brassica napus L.) under rainfed conditions. Journal of Zhejiang University - Science B, Hangzhou, v. 8, n. 10, p. 731-737, 2007.

ALI, A.; MUNIR, M. K.; MALIK, M. A.; SALEEM, M. F. Effect of different irrigation and nitrogen levels on the seed and oil yield of canola (Brassica napus L.). Pakistan Journal of Agricultural Sciences, Faisalabad, v. 40, n. 3-4, p. 137-139, 2003.

ALLEN, R. G.; PEREIRA, L. S.; RAES, D.; SMITH, M. Evapotranspiración del cultivo: guías para la determinación de los requerimientos de agua de los cultivos. Roma: Organización de las Naciones Unidas para la Agricultura, 2006. 298 p. (Estudio fao riego y drenaje, 56).

BARBOSA, J. C.; MALDONADO JÚNIOR, W. AgroEstat - sistema para análises estatísticas de ensaios agronômicos. versão 1.0. Jaboticabal: FCAV/UNESP, 2011.
BATAGLIA, O. C.; FURLANI, A. M. C.; TEIXEIRA, J. P. F.; FURLANI, P. R.; GALLO, J. R. Métodos de análise química em plantas. Campinas: Instituto Agronômico, 1983. 48 p. (Boletim técnico, 78).

BRENNAN, R. F.; BOLLAND, M. D. A. Comparing the nitrogen and phosphorus requirements of canola and wheat for grain yield and quality. Crop and Pasture Science, Collingwood, v. 60, n. 6, p. 566-577, 2009.

CANTARELLA, H.; PROCHNOW, L. I. Determinação de sulfato em solos. In: RAIJ, B. van; ANDRADE, J. C.; CANTARELlA, H.; QUAGGIO, J. A. (Ed.). Análise química para avaliação da fertilidade de solos tropicais. Campinas: Instituto Agronômico, 2001. p. 225-230.

CHEEMA, M. A.; MALIK, M. A.; HUSSAIN, A.; SHAH, S. H.; BASRA, S. M. A. Effects of time and rate of nitrogen and phosphorus application on the growth and seed and oil yields of canola (Brassica napus L.). Journal of Agronomy and Crop Science, Saskatoon, v. 186, n. 2, p. 103-110, 2001.

EMPRESA BRASILEIRA DE PESQUISA AGROPECUÁRIA - EMBRAPA. Sistema brasileiro de classificação de solos. Rio de Janeiro: Embrapa Solos, 2006. $306 \mathrm{p}$.

EPSTEIN, E.; BLOOM, A. J. Nutrição mineral de plantas: princípios e perspectivas. 2. ed. Londrina: Editora Planta, 2006. 403 p.

ERIKSEN, J.; OLESEN, J. E.; ASKEGAARD, M. Sulphate leaching and sulphur balances of an organic cereal crop rotation on three Danish soils. European Journal of Agronomy, Montpellier, v. 17, n. 1, p. 1-9, 2002.

FISMES, J.; VONG, P. C.; GUCKERT, A.; FROSSARD, E. Influence of sulfur on apparent N-use efficiency, yield and quality of oilseed rape (Brassica napus L.) grown on a calcareous soil. European Journal of Agronomy, Montpellier, v. 12, n. 2, p. 127-141, 2000.

HOCKING, P. J.; RANDALL, P. J.; De MARCO, D.; BAMFORTH, I. Assessment of the nitrogen status of field-grown canola (Brassica napus) by plant analysis. Australian Journal of Experimental Agriculture, Collingwood, v. 37, n. 1, p. 83-92, 1997.

IBRAHIM, A. F.; ABUSTEIT, E. O.; EL-METWALLY, El-M. A. Response of rapeseed growth, yield, oil content and its fatty acids to nitrogen rates and application times. Journal of Agronomy and Crop Science, Saskatoon, v. 162 , n. 2, p. 107-112, 1989.

JAN, A.; AHMAD, G.; ARIF, M.; JAN, M. T.; MARWAT, K. B. Quality parameters of canola as affected by nitrogen and sulfur fertilization. Journal of Plant Nutrition, Philadelphia, v. 33, n. 3, p. 381-390, 2010. 
KHAN, N.; JAN, A.; IHSANULLAH, I.; KHAN, A.; KHAN, N. Response of canola to nitrogen and sulphur nutrition. Asian Journal of Plant Sciences, Faisalabad, v. 1, n. 5, p. 516-518, 2002.

KOPRIVOVA, A.; SUTER, M.; CAMP, R. O. den; BRUNOLD, C.; KOPRIVA, S. Regulation of sulfate assimilation by nitrogen in Arabidopsis. Plant Physiology, Florence, v. 122, n. 3, p. 737-746, 2000.

MALHI, S. S. Influence of four successive annual applications of elemental $\mathrm{S}$ and sulphate-S fertilizers on yield, S uptake and seed quality of canola. Canadian Journal of Plant Science, Ottawa, v. 85, n. 4, p. 777-792, 2005.

MALHI, S. S.; GILL, K. S. Cultivar and fertilizer S rate interaction effects on canola yield, seed quality and $\mathrm{S}$ uptake. Canadian Journal of Plant Science, Ottawa, v. 86, n. 1, p. 91-98, 2006.

MALHI, S. S.; GILL, K. S. Interactive effects of N and S fertilizers on canola yield and seed quality on S-deficient Gray Luvisol soils in northeastern Saskatchewan. Canadian Journal of Plant Science, Ottawa, v. 87, n. 2, p. 211-222, 2007.

MALIK, M. A.; AZIZ, I.; KHAN, H. Z.; WAHID, M. A. Growth, seed yield and oil content response of canola (Brassica napus L.) to varying levels of sulphur. International Journal of Agriculture \& Biology, Faisalabad, v. 6, n. 6, p. 1153-1155, 2004.

ÖZTÜRK, Ö. Effects of source and rate of nitrogen fertilizer on yield, yield components and quality of winter rapeseed (Brassica napus L.). Chilean Journal of Agricultural Research, Chillán, v. 70, n. 1, p. 132-141, 2010.

RAIJ, B. van; ANDRADE, J. C.; CANTARELlA, H.; QUAGGIO, J. A. Análise química para avaliação da fertilidade de solos tropicais. Campinas: Instituto Agronômico, 2001. 284 p.
RAIJ, B. van; CANTARELLA, H.; QUAGGIO, J. A.; FURLANI, A. M. C. Recomendações de adubação e calagem para o Estado de São Paulo. 2. ed. Campinas: IAC, 1996. 285 p. (IAC. Boletim técnico, 100).

RATHKE, G. W.; CHRISTEN, O.; DIEPENBROCK, W. Effects of nitrogen source and rate on productivity and quality of winter oilseed rape (Brassica napus L.) grown in different crop rotations. Field Crops Research, Amsterdam, v. 94, n. 2-3, p. 103-113, 2005.

RHEINHEIMER, D. S.; ALVAREZ, J. W. R.; OSORIO FILHO, B. D.; SILVA, L. S.; BORTOLUZZI, E. C. Resposta de culturas à aplicação de enxofre e a teores de sulfato num solo de textura arenosa sob plantio direto. Ciência Rural, Santa Maria, v. 35, n. 3, p. 562-569, 2005.

RUBIO, G.; SCHEINER, J. D.; TABOADA, M. A.; LAVADO, R. S. Distribución de nitrógeno, fósforo y azufre en un cultivo de colza: efectos sobre el ciclado de nutrientes. Ciência del Suelo, Buenos Aires, v. 25, n. 2, p. 189-194, 2007.

SCHERER, H. W. Sulphur in crop production - invited paper. European Journal of Agronomy, Montpellier, v. 14, n. 2, p. 81-111, 2001.

SILVA, D. J.; QUEIROZ, A. C. Análise de alimentos: métodos químicos e biológicos. 3. ed. Viçosa: UFV, 2002. $235 \mathrm{p}$.

TOMM, G. O. Cultivo de canola. Embrapa Trigo, nov. 2007. (Sistemas de Produção, 3). Disponível em: $<$ http:// sistemasdeproducao.cnptia.embrapa.br/FontesHTML/ Canola/CultivodeCanola/index.htm>. Acesso em: 15 mar. 2012.

ZHAO, Y.; XIAO, X.; BI, D.; HU, F. Effects of sulfur fertilization on soybean root and leaf traits, and soil microbial activity. Journal of Plant Nutrition, Philadelphia, v. 31, n. 3, p. 473-483, 2008. 
